\title{
Crítica Genética, psicanálise e neurociência
}

Philippe Marie Willemart ${ }^{1}$

\begin{abstract}
Eu tinha vindo a Balbec para encontrar o prazer de brincar com jovens meninas menos fatais para a vida espiritual, para a qual pelo menos ele permanece estrangeiro, do que a amizade cujo esforço é fazer com que sacrifiquemos a única parte real e incomunicável (que não seja por meio da arte) de nós mesmos, para um eu superficial, ${ }^{2}$
\end{abstract}

OS ENCONTROS COM AMIGOS IMPEDEM O ESCRITOR DE SE DEDICAR À SUA ARTE, é o que Barthes repete em Os Fragmentos de um Discurso amoroso, quando dele se insurge contra a amizade: "a amizade mundana é epidemia: todo mundo pega, como uma doença" ${ }^{3}$. Talvez ele a comparasse hoje com a pandemia de coronavírus.

Neste artigo, não vou endossar a concepção de amizade no sentido proustiano-barthesiano mas, pelo contrário, irei ao encontro de pesquisadores incomuns na área de crítica literária para trazer elementos novos nos estudos sobre manuscritos de escritores e, assim, aumentar nossa abertura ao Outro. Lembrarei brevemente relações das pesquisas de Einstein com a crítica genética desenvolvidas noutra revista e detalharei algumas pesquisas das neurociências articuladas à teoria psicanalítica, que se situam em área de fronteira com a crítica genética.

\section{O espaço-tempo}

Apesar das primeiras descobertas de Einstein terem mudado nossa concepção de tempo, não sabemos como integrar essa visão do espaço-tempo em nossas pesquisas e continuamos a manter a concepção newtoniana de tempo contínuo, a mesma para todos, aquela que flui através de horas e dias.

Proust, pelo contrário, não hesitou em descrever a quarta dimensão da igreja de Combray, em sintonia com a ótica einsteiniana:

Tudo aquilo e mais ainda os objetos preciosos, oriundos de personagens que para mim eram quase personagens de lenda [...] e por causa das quais eu avançava pela igreja [...], como por um vale visitado pelas fadas, [...] tudo aquilo fazia da igreja, para mim, alguma coisa de inteiramente diverso do resto da cidade: um edifício que ocupava, por assim dizer, um espaço de quatro dimensões - a quarta era a do Tempo -, e impelia através dos séculos sua nave que, de abóbada em abóbada, de capela em capela, parecia vencer e transpor não simplesmente alguns metros, mas épocas sucessivas de onde saia triunfante ${ }^{4}$.

No último volume de sua obra, Proust fortaleceu sua posição inventando a psicologia no espaço, imaginando uma nova relação entre os homens, onde circulando uns em torno dos outros, como a Terra ao redor do Sol, estes formam um novo espaço, que aumenta à medida em que acontecem as revoluções ao redor do ente querido, o objeto lido, a estátua admirada ou a pintura notada, sabendo que todos os homens e objetos são espaço-tempo, caminhando ou não, e constituem o espaço-tempo do Universo.

\footnotetext{
${ }^{1}$ Professor Titular em literatura francesa do Departamento de Letras Modernas da Universidade de São Paulo (USP). Email: plmgwill@gmail.com.

${ }^{2}$ PROUST, 680 e

${ }^{3}$ BARTHES, R. Euvres complètes. Paris: Seuil, 2002, p. 177.

${ }^{4}$ Proust, M. No caminho de Swann, Em busca do tempo perdido. Trad. Mario Quintana. São Paulo: Globo, 2006, p. 90.
} 
Cada volta é uma fatia do espaço-tempo vivida pelo sujeito, cujo acúmulo, semelhante às pernas de pau do Duque de Guermantes ${ }^{5}$, eleva-o a um nível extremamente alto, que pode assustá-lo, mas que também aumenta seu assento, o espaço ocupado, ao contrário do que descreve o narrador que vê um espaço reduzido.

Como considerar a relação entre o escritor e seu objeto, seja um romance, um poema ou uma peça, na concepção do espaço-tempo quadri-dimensional?

A frase escrita deverá ser considerada quer sem conexão imediata com a anterior, dado os intervalos entre elas na memória da escrita, quer como uma metáfora para eventos anteriores, quer como resultado do cálculo das probabilidades de revoluções (no sentido astronômico ou proustiano do termo) operadas pelo escritor em torno de seu objeto após a sentença anterior.

Portanto, as rasuras não significam mais uma recusa ou uma negação da palavra substituída, mas a adição ou a supressão de um espaço-tempo que retorna ou não ao vasto conjunto virtual espaço-tempo, outro nome para a memória da escrita.

\section{As neurociências}

As recentes descobertas sobre o cérebro nos encorajam a examinar como elas podem ajudar o geneticista a progredir na compreensão do que está acontecendo no manuscrito, como elas diferem dele e como elas se parecem com ele.

A teoria psicanalítica elaborada por Freud, Lacan, Soler e muitos outros tenta identificar a psique do ser falante e sua relação com o inconsciente, e para Freud, pelo menos, inclui as pesquisas sobre a biologia do cérebro, mas a teoria no seu conjunto parece se opor à abordagem do cérebro pelas neurociências, que dão outro significado à palavra "inconsciente", também chamada de "inconsciente cognitivo", muito próxima do préconsciente freudiano.

Analisarei duas posições diferentes sobre as relações entre psicanálise e neurociências que nos permitirão avaliar com mais precisão a aproximação entre a neurociência e a abordagem dos textos literários através do estudo dos manuscritos.

\section{Posição de Jean-Pierre Bourgeois}

Hoje, a neurociência não só observa imagens, mas também olha para os processos eletroquímicos que regem o cérebro, matiza os achados da psicanálise e força-a a rever algumas de suas posições. Se seguirmos o neurobiólogo Jean-Pierre Bourgeois, os dois conhecimentos não se opõem de outra forma senão em seu método: Não vejo nenhuma contradição epistemológica entre o dizer psicanalítico sobre o aparelho psíquico e o dizer neurobiológico sobre a evolução da sinaptoarquitectonia. As diferenças são apenas metodológicas. ${ }^{6}$ No curto

\footnotetext{
5 "Acabava de compreender por que o duque de Guermantes, a quem admirava, vendo sentado, por haver envelhecido tão pouco, apesar de ter sobre si muitos anos mais do que eu, mal se erguera e quisera permanecer de pé, logo vacilara nas pernas [...] como se os homens se equilibrassem sobre pernas de pau vivas, sempre crescentes, algumas mais altas que campanários, tornando-lhes difícil e perigosa a marcha, e de onde subitamente caem". Idem. Du côté de chez Swann, À la recherche du temps perdu Combray Premières épreuves corrigées 1913 Introduction et transcription de Charles Méla. Paris: Gallimard, 2013, p. 406.

${ }^{6}$ O sinaptoarquitectonia cortical é a organização geométrica tridimensional das árvores axonais e dendríticas formando redes neurais, e também a distribuição e flutuações de inúmeros estados funcionais de sinapses. (BOURGEOIS, J-P. Synaptoarchitectonie, sujets et questions interfaces. In: GOLSE, B., PUTOIS, O.; VANIER, Al.. Epistémologie et méthodologie en psychanalyse et en psychiatrie, Pour un vrai debat avec les neurosciences. Paris: Erès, 2017, p. 51)
} 
espaço de tempo da sessão, o psicanalista "ouve" a experiência do analisando, o sujeito; um discurso global do sujeito, variável (ou não), fluido (ou não), qualitativo, simbólico, manifestando todos os tempos imbricados de sua história. $\mathrm{O}$ analista e o analisando não têm nada a ver com sinaptoarquitectonia, sinapses, moléculas, atividades e ruído de fundo neurofisiológico ${ }^{7}$.

De fato, as observações do cérebro mostram a complexidade absoluta do agir cerebral que não deve ser de interesse do psicanalista a priori:

estados mentais do indivíduo ou do aparelho psíquico do sujeito, como se gostaria, são construídos neste milhar de causalidades, nas redes, muito dinâmicas de genes e epigênese genômica e sináptica, e o fluxo constante de interações com o meio ambiente [...]. Esta é uma pequena visão da complexidade biológica do córtex cerebral que os neurobiólogos enfrentam hoje $^{8}$.

\section{A posição de Erançois Ansermet e Pierre Magistretti}

O neurocientista Pierre Magistretti e o psicanalista François Ansermet se debruçaram já em 2004 e provavelmente muito antes, sobre a relação entre psicanálise e neurociência, notadamente em Para cada um seu cérebro: plasticidade neuronal e inconsciente, no qual tentam forjar relações entre os dois saberes enquanto notam sua incomensurabilidade primária.

Eles continuam refletindo sobre esse tema na obra coletiva Neurociências e Psicanálise (2010) e numa outra organizada por Gorse, Putois e Vanier (2017), onde Bourgeois intervém, e finalmente em dois vídeos disponibilizados recentemente no YouTube (2018 e 2019).

Usar o condicional me faz repetir a questão: não haveria coincidência entre o rastro mnésico, a imagem e o significante, apenas no momento da primeira inscrição, quando os três elementos convergem e não mais depois, já que o fator temporal intervém? O jogo muda a ponto de Ansermet concluir:

Através dos mecanismos da plasticidade, a experiência deixa um rastro. Este rastro se apresenta sob a forma de conjuntos de sinapse facilitados, que constituem, assim, o correspondente neural de uma experiência ou de um objeto da realidade externa. A reassociação dos rastros introduz, assim, um grau de liberdade essencial para o surgimento da singularidade. [...] Posteriormente, no entanto, esses rastros combinam entre eles para formar novos rastros que não estão mais diretamente relacionados com as experiências ou as percepções iniciais. Estes novos conjuntos de neurônios incluem os anteriores numa forma renovada. [...] Por isso, nos deparamos com um paradoxo que implica a plasticidade: a inscrição da experiência, através da reassociação de rastros e do fenômeno da reconsolidação, separa da experiência, criando assim uma descontinuidade. A reassociação dos rastros introduz, assim, um grau de liberdade que é essencial para o surgimento da singularidade?

Ansermet não insiste mais na sobreposição dos dois saberes como fez em 2004, mas sobre sua intersecção manifesta nos rastros psíquicos, sinápticos e mnemônicos ${ }^{10}$. Ele lembra o conceito freudiano que particularmente

\footnotetext{
${ }^{7}$ Ibidem, p. 68.

${ }^{8}$ Ibidem, p. 61.

${ }^{9}$ ANSERMET, F. Neurosciences et psychanalyse. Paris: Odile Jacob, 2010a, p. 16-18

${ }^{10}$ Idem. Continuité et discontinuité, entre neurosciences et psychanalyse. Fondation Agalma: 24 de maio de 2018. Disponível em: https:// www. youtube. com/watch?v=-3GNY_BKif4, acesso 15 dez 2019.
} 
ecoa nessas implicações fisiológicas, o de pulsão, definida como um conceito limítrofe entre o psíquico e o somático ${ }^{11}$. A pulsão é um conceito altamente fisiológico porque participa, através de sua tendência à descarga, à regulação da homeostase geral do corpo ${ }^{12}$. Ele termina reencontrando a raiz de nossa liberdade de agir:

O terceiro paradoxo da plasticidade é o da mudança permanente que produz esse tipo de encadeamento, o que significa que nunca se usa duas vezes o mesmo cérebro, e que se acaba por ser biologicamente determinado para não ser totalmente biologicamente determinado. Nesse sentido, estamos determinados a ser livres, ou geneticamente determinados a não sermos determinados ${ }^{13}$.

Na palestra ministrada em Paris, em 29 de maio de 2019, O sintoma entre a neurociência e a psicanálise, Ansermet retoma alguns dos argumentos de 2010 e, contrariamente a Bourgeois, incentiva os neurocientistas a ingressar no campo psicanalítico num ponto definido, não sem destacar a diferença entre o inconsciente freudiano e o inconsciente cognitivo da neurociência. ${ }^{14}$ Pede que eles não procurem o gene de tal doença ou dispositivo mental como a esquizofrenia, por exemplo, pesquisas que enganam, pois as doenças sempre dependem de vários fatores e não de um, mas que procurem como articular o vivo e o humano ou como vislumbrar a descontinuidade entre o cérebro completamente regulado e o transtorno inerente ao humano, ${ }^{15}$ reforçando a queixa do psiquiatra Michel le Moal que no mesmo livro lamenta que "um acúmulo ilimitado de dados e resultados contrasta com um vácuo epistemológico e teórico" na neurociência ${ }^{16}$.

Parece claro que devemos adotar a posição interdisciplinar de Ansermet e não a de cada um na sua disciplina de Bourgeois e nos perguntar como as descobertas da neurociência afetam a abordagem genética da literatura.

\footnotetext{
${ }^{11}$ (FREUD, 1919)

12 (ANSERMET em GOLSE, 2017, 19)

${ }^{13}$ Ibidem, p. 27.
}

${ }^{14} \mathrm{O}$ primeiro eixo diz respeito ao fato de que o inconsciente cognitivo opera por mecanismos comuns aos fenômenos conscientes, enquanto o inconsciente freudiano prossegue de uma adimensionalidade específica e que a teoria psicanalítica define como processo primário: um processo marcado pela atemporalidade, a não espacialidade, a ausência de contradição e ausência de negação, com uma tendência à descarga, segundo o princípio do prazer. O segundo eixo é que o inconsciente cognitivo é constituído - através dos processos de plasticidade neuronal - de representações mentais que permanecem em relação direta e em continuidade com as dimensões da realidade externa que participaram em produzi-las: esta é uma grande distinção com o inconsciente freudiano, que prossegue ao contrário de uma descontinuidade, em consequência da reassociação de rastros, que também resulta da plasticidade e reconsolidação. O inconsciente cognitivo estaria, portanto, do lado da continuidade, enquanto do lado da descontinuidade encontraríamos o inconsciente freudiano, que, consequentemente, não pode ser considerado como um sistema de memória. (ANSERMET François. Neurosciences et psychanalyse. Paris: Odile Jacob, 2010, p. 195-196)

${ }^{15}$ As pressões ambientais, distúrbios internos, idade, desgaste dos ajustes locais produzem mudanças, por vezes lentas e não percebidas pelo sujeito, em pontos de equilíbrio homeostático; as constantes se movem. É essencial compreender que está sendo estabelecido um novo equilíbrio, resultado de forças opostas, aqueles que se afastam dos mecanismos fisiológicos e aqueles que tentam trazer de volta o equilíbrio inicial. Este estado é chamado de "alostasia" (nível caro de adaptação, além das regulamentações fisiológicas específicas da homeostase). Os ajustes não são mais locais, mas envolvem múltiplos sistemas, dependendo da história do assunto; a necessidade biológica é antecipada. Essa condição custa ao corpo e ao indivíduo. É uma porta de entrada para o estado da doença (ANSERMET François. Neurosciences et psychanalyse. Paris: Odile Jacob, 2010, p. 116)

${ }^{16}$ Ibidem, p. 136. 
Não se trata de encontrar o gene da criação do autor estudado através de seus manuscritos, mas de compreender como vislumbrar a descontinuidade entre o cérebro totalmente regulado e a desordem inerente ao humano manifestada no manuscrito.

Não há dúvida de que há desordem nos manuscritos dos escritores. Basta olhar para a continuação dos fólios do primeiro capítulo de Herodias de Flaubert, que exigiu um ano de estudos extensos para encontrar a continuação exata e possível (!) dos fólios:
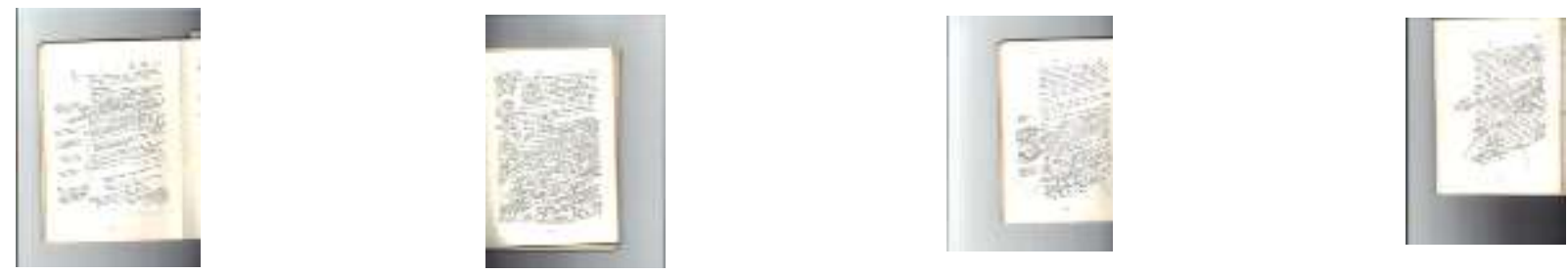

ou a ordem dos cadernos proustianos, um assunto de controvérsia entre os críticos.

Se olharmos para a escritura de um fólio de Proust, o número de rasuras, ainda mais numerosas nas provas devolvidas à editora, prova a desordem não do manuscrito, mas do pensamento do escritor. $\mathrm{O}$ escritor intuitivamente sabe o que provavelmente quer, Proust queria construir um romance estruturado como uma catedral ${ }^{17}$, mas acaba oferecendo um vestido remendado como o de Françoise. ${ }^{18}$

No entanto, sejamos cautelosos com a apreciação do autor de sua própria obra: em uma análise cuidadosa da Busca do Tempo Perdido, Geneviève Henrot revelou o vigamento não de um edifício, mas da memória, ${ }^{19}$ estrutura provavelmente ignorada pelo autor.

O escritor muitas vezes tem apenas uma vaga ideia de como vai realizar seu trabalho e o descobre apenas com sua caneta ou o teclado, palavra por palavra, expressão após expressão. A escrita não serve para reproduzir seu pensamento, mas para desdobrá-lo, descobri-lo e ordená-lo numa narrativa, daí os muitos ensaios ou versões em cadernos ou em fólios. Quanto mais um escritor escurece seu papel ou preenche páginas em seu caderno ou no PC, mais chances terá de descobrir seu estilo e seu pensamento que provém de sua escritura.

Como a neurociência fornece aos geneticistas ferramentas ou conceitos para entender melhor a escrita que ocorre no manuscrito?

Devemos retornar aos três tipos de rastros que marcam o escritor em qualquer evento vivido ou percepção proveniente da leitura, da sensação, do toque ou do ouvir: a inscrição sináptica ou a impressão material no corpo (no ponto de encontro dos neurônios no cérebro), o rastro mnésico (ligado à imagem de um evento da memória) e o significante (forma e sintaxe da língua), cada um dos rastros sendo anexados à pulsão correspondente. Os rastros são mantidos num dos três níveis enquanto gradualmente perdem seus vínculos com os outros componentes ao longo do tempo. Tudo o que resta, então, é uma imagem, um significante ou uma inscrição sináptica, às vezes ainda a conexão entre os rastros significante e imagético. Mas seja qual for o resto ou o desperdício dessas percepções, o conjunto se verá metaforicamente falando numa esfera, a memória

\footnotetext{
${ }^{17}$ FRAISSE, Luc. L'ouvre cathédrale : Proust et l'architecture médiévale. Paris: Corti, 1990.

${ }^{18}$ Os seres simples que conosco convivem possuindo certa intuição de nossas ocupações tarefas [...], eu trabalharia a seu lado, e quase à sua imitação do que outrora fazia: agora muito velha, já não tinha vista para nada; pois, pregando aqui e ali uma folha suplementar, eu construiria meu livro, não ouso dizer ambiciosamente como uma catedral, mas modestamente como um vestido. (Proust, M., O tempo redescoberto, Em busca do tempo perdido. Trad. Lúcia Miguel Pereira. São Paulo: Globo, 2013, p. 389)

${ }^{19}$ Foi no congresso proustiano em Cerisy-la-Salle em 1997. (HENROT, Geneviève, Poétique et réminiscence : charpenter le temps, Marcel Proust 3, Nouvelles directions de la recherche proustienne 2. Paris : Minard, 2001, p. 253)
} 
da escrita que identifico com o mundo atômico de Rovelli, ${ }^{20}$ sabendo que adiciono aqui um elemento, a inscrição sináptica.

A rasura pode, portanto, ser entendido como causado pela lembrança inesperada de um desses rastros. O geneticista pode se perguntar de que rastro se trata.

Para a memória da imagem, será fácil: Proust, com arte sutil e persuasiva remonta às origens do gozo experimentado comendo a madeleine quando a mergulha várias vezes numa xícara de chá.

Para o rastro-significado, seria necessário voltar aos processos associativos que o fizeram surgir. Raramente, o escritor irá comunicá-lo ao leitor ou ao crítico, já que nem sempre ele se lembra disso. No máximo, o neurocientista será capaz de saber quais áreas de neurônios são ativadas quando a palavra é falada.

Para o rastro sináptico, ninguém, normalmente nem o autor nem o crítico serão capazes de suspeitar de sua origem, a menos que esteja associado a uma lembrança marcante, portanto a uma imagem de memória que, mantendo sua conexão com o evento, tem permanecido no pré-consciente e facilmente será lembrada pelo escritor.

Ao contrário do neurocientista que deve multiplicar o número de imagens tanto quanto pode para saber como o cérebro reage numa determinada atividade, o geneticista tem a seu favor o trabalho publicado, resultado de anos de trabalho do escritor e, muitas vezes, de todos os manuscritos onde ele pode ver os caminhos inesgotáveis que se abrem para outros desenvolvimentos ou que terminam num beco.

Em outras palavras, o geneticista não será capaz de determinar todos os caminhos que levam ao texto, mas descobrirá que as frases ou parágrafos não se alinham um atrás do outro, nem os episódios são articulados entre eles à maneira de um teorema, mas seguem uma lógica não linear, se não caótica, que não será compreendida até o final do romance. Pude demonstrar como o texto publicado de Herodias pode ser entendido como a metáfora ou a metonímia de versões sucessivas.

Como encarar o manuscrito sob a perspectiva da neurociência? Tanto o geneticista quanto o neurocientista querem saber como o cérebro funciona.

Se nem o psicanalista, segundo Bourgeois, nem o escritor se importarem com a neurociência, o geneticista se preocupará como Ansermet porque confrontado diretamente com a criação de uma escritura, ele levará em conta a luta do escritor que tenta se libertar das redes manipuladores do cérebro, que seriam chamados de algoritmos hoje ${ }^{21}$, para estabelecer sua escritura.

Se seguirmos a distinção de Gerald Edelman entre consciência superior e consciência primária ${ }^{22}$, a maioria de nossas decisões ficaria dentro da consciência primária, embora também sabemos que elas dependem principalmente do inconsciente. Na hora da escolha de substituir uma rasura ou quando ele pensa que tem uma nova ideia, o escritor não decide sozinho. Impulsionado pelo prazer antecipado ${ }^{23}$, por seus hábitos (algoritmos

${ }^{20}$ Para uma hipotética vista muito fina que veria tudo, não haveria tempo que passa e o Universo seria um bloco de passado, presente e futuro. [...] Habitamos o tempo porque vemos somente uma imagem enfraquecida do mundo [...] é desta imprecisão turva do mundo que provém nossa percepção do passar do tempo. (ROVELLI, C. Sept brèves leçons de physique. Paris: Odile Jacob, 2015, p. 71)

21 "uma sequência finita e inequívoca de instruções para chegar a um resultado com base em dados fornecidos na entrada". (CNIL-França, 2017)

${ }^{22}$ A consciência primaria é o estado que consiste a ser mentalmente consciente das coisas do mundo, a saber das imagens mentais no presente [...] ela não está acompanhada do sentimento de ser socialmente definido, implicando o conceito do passado e do futuro. Ela existe principalmente no presente rememorado. (compartilhamos esta consciência com os primatas superiores) Pelo contrário, a consciência de ordem superior implica a aptidão a ser consciente de ser consciente, e ela permite o reconhecimento pelo sujeito pensante de seus atos e afeições .[...] No mínimo, ela exige a aptidão semântica [...] e sob a forma mais desenvolvida, ela necessita a aptidão linguística. (EDELMAN, Gerald. Plus vaste que le ciel, Une nouvelle théorie générale du cerveau. Paris: Odile Jacob, 2004, p. 24)

${ }^{23}$ ANSERMET François. Neurosciences et psychanalyse. Paris: Odile Jacob, 2010, p. 29. 
que o levam e que ele frequentemente ignora) a tradição literária anterior, seus próprios escritos ou as ansiedades de sua comunidade, pelo jogo de palavras, pela sintaxe e pelas ressonâncias da linguagem, ele compõe sua narrativa. ${ }^{24}$

O geneticista não pode, portanto, permanecer insensível às contribuições da neurociência e mesmo que em sua busca por processos criativos possa imitar o psicanalista, que deve ignorar o ambiente, o que não é óbvio, o geneticista pode, não mais do que o analisando, atribuir as mudanças notadas apenas a um evento biográfico ou histórico da vida do escritor. Em termos ansermetianos, terá que admitir a descontinuidade e a ignorância das causas da mudança ou da atribuição de efeitos a uma determinada causa.

O exemplo da morte no mar do ex-piloto de Proust, Agostinelli, que se tornou um aviador no início da guerra 14-18, é um exemplo claro. É verdade que esta morte catalisou este evento sobre a personagem Albertine e certamente forçou Marcel Proust a partir de outra base neural para continuar seu novo texto.

A morte de seu amante foi o gatilho, eu teria dito antes dessa aproximação com a neurociência. Mas, com o aporte da neurociência, posso dizer que o gatilho foi causado pela junção dos três rastros que afetaram Marcel Proust, o evento ou a morte de Agostinelli associada ao conceito de sofrimento ressentido ao nível do corpo. A junção inicial dos três rastros se dilatou, o significante morte se aplicou a Albertine, o significante sofrimento ao herói Marcel junto com a lembrança da morte, mas o sofrimento ressentido no momento por Proust ficou incrustado no cérebro como ele dirá mais tarde.

O estudo da frase perturbadora para o crítico no livro 54: "Depois de muitos capítulos, farei tudo diferente onde Albertine nunca mais será discutida." destaca a difícil separação entre o escritor que sentiu a perda de Agostinelli, quando os três rastros foram sobrepostos, e o autor que superou ou sublimou sua paixão por escrever fazendo de Albertine uma personagem completamente diferente, "a grande deusa do Tempo" 25 .

Supomos que o rastro psíquico de sofrimento impresso na mente de Marcel Proust assim que o avião caiu, embutido na memória, tornou-se no romance a queda fatal de Albertine a cavalo. Mas que caminho entre os dois eventos! Não só esse acidente, que se transformou em queda de cavalo, pega o que já foi contado sobre a personagem Maria, que se tornou Albertine do plano de 1913 do caderno 46 antes do acidente de Agostinelli ${ }^{26}$, mas também o presente do choque emocional significado desde a fuga do ex-motorista como a de Albertine, e o futuro que se seguiu na construção de Albertine.

A queda fatal de Agostinelli não explica a queda igualmente mortal de Albertine, no sentido de que não é a única causa. Em vez disso, eu diria que esta última é sobreposta à primeira, tem relações de vizinhança, onde os eventos podem atrair uns aos outros a ponto de se sobreporem, como o herói aponta quando descobre a partida de Albertine:

E, com efeito, eram todas as inquietações experimentadas na infância, que, ao chamado de nova angústia, haviam acudido para reforçá-la, e amalgamar-se a ela numa massa homogênea que me sufocava ${ }^{27}$.

O narrador insiste em colocar no mesmo plano sem preocupação com cronologia ou espaço todos os sofrimentos experimentados, dando assim uma base literária à tese de Ansermet sobre a ligação entre rastros psíquicos, mnésicos e sinápticos ou entre os inconscientes freudianos e cognitivos:

\footnotetext{
24 "Do ponto de vista psicanalítico, o escritor tomará suas decisões e escreverá empurrado pelos 'elementos da pulsão, ou seja, a re-representação do estado somático [...] 'S' e a representação psíquica da experiência [...] 'R"' (ANSERMET, 2010b, 51)

${ }^{25}$ Proust, 2011, 448

${ }^{26}$ (Proust, 1988, 1239)

${ }^{27}$ Idem. A fugitiva, Em busca do tempo perdido. Trad. Carlos Drummond de Andrade. São Paulo: Globo, 2012, p. 27.
} 
Evidentemente, o golpe físico no coração que um tal afastamento produz, e que, por esse terrível poder registrador que tem o corpo, converte a dor em algo de contemporâneo de todas as épocas de nossa vida em que sofremos ${ }^{28}$.

Proust encontra o conceito de "memória escrita" ou de memória virtual, ou de vastos conjuntos virtuais", mas aplica o conceito à psique de acordo com Ansermet ou ao rastro psíquico, aproximando-se ainda mais da teoria einsteiniana e da teoria quântica com loops. ${ }^{29}$ Esse conceito de alguma forma cruza de uma certa maneira o da ausência de um "agora uniforme" da física einsteiniana para a qual o tempo não passa. ${ }^{30}$

A constante mudança do cérebro, resultado de eventos cotidianos de onde quer que venham, favorece as revisões contínuas e explica as rasuras subsequentes. A plasticidade do cérebro acentua a liberdade do escritor cuja arte é precisamente devida a seu esforço mais ou menos árduo para se libertar de seu passado, de sua vida de paixões e de seus hábitos para se tornar scriptor a serviço da linguagem utilizada, de seus personagens e de sua narrativa. O escritor, como Picasso pintando frente à câmera de Clouzot (1956), terá que destruir constantemente para criar, isto é, para diluir os laços entre os rastros sinápticos e mnésicos e encontrar uma nova expressão de rastro-significante. É outra maneira de definir o conceito de criação.

Foi Flaubert que aconselhava à sua amante, Louise Colet, que queria ser poeta, a não confiar em seus sentimentos para escrever, ou seja, nos rastros mnésicos e sinápticos. ${ }^{31}$

A óbvia intersecção entre rastros psíquicos, sinápticos e mnésico aumenta as ligações entre a rasura ligada à memória e aos outros dois rastros, deixando aberto o campo para o inconsciente freudiano atemporal e a-espacial.

Levando em conta as descobertas da neurociência, o geneticista saberá distinguir os rastros e como eles se articulam, e por isso, entenderá melhor o mecanismo da escritura e da rasura sem preocupar-se muito com rastros sinápticos que não tem como detectar, nem como o cérebro do escritor funciona.

\footnotetext{
${ }^{28}$ Ibidem, loc. cit.

29 "A gravidade quântica com loops procura combinar a relatividade geral e a mecânica quântica diretamente sem acrescentar nada. [...] Mas as consequências são radicais: uma modificação profunda da estrutura da realidade. [...] A predição central da teoria com loops é, portanto, que o espaço físico não é contínuo, ele não é divisível ao infinito. É formado de grãos, de «átomos de espaço ». Estes grãos são muito pequenos: um bilhão de vezes menores que o menor dos núcleos atômicos". (ROVELLI, C. Sept brèves leçons de physique. Paris: Odile Jacob, 2015, p. 50-51)

30 o tempo não corre, sua passagem é uma ilusão e não é irreversível se o consideramos na sua amplidão. O tempo, fundamentalmente reversível, faz corpo com o espaço e não é um dado separado dos acontecimentos. (DAMOUR, T. http://www.doublecause.net/index.php?page=Thibault_ Damour.htm, 2011, p. 14) As mudanças no tempo sempre estão acompanhadas de espaços diferentes que se sobrepõem ao longo das pernas de pau respectivas. (como as do duque de Guermantes) Como sempre levamos nosso passado conosco, o presente não existe, ou melhor, existe, mas jamais independentemente do passado; faz um com o passado.

Neste sentido, « não é mais possível definir o agora ». (DAMOUR, T. http://www.doublecause.net/index.php?page=Thibault_, 2011.)

31 "Louise, tire então sinistro e acrescente tranquilo quando se pinta de forma tão magistral, será que somos participantes do quadro? Esta única palavra de sentimentos e de apreciação moral estraga minha impressão [...] a Poesia, que é um maneira de ver, alcança seus resultados externos apenas por uma convicção entusiasmada da Verdade. [...]. - bem, será que você não tem, no mais profundo de ti, (pois não é nem o coração nem a cabeça), mas mais adiante, [...] como um grande lago onde tudo é refletido, onde tudo brilha, um murmúrio perpétuo que quer se espalhar, uma fluidez que quer sair?" (Flaubert, 1853, Amigos de Flaubert,-1970-Boletim No36, 33)
} 


\section{Bibliografia}

ANSERMET, François et MAGISTRETTI, Pierre À chacun son cerveau: plasticité neuronale et inconscient. Paris: Odile Jacob, 2004.

ANSERMET François. Neurosciences et psychanalyse. Paris: Odile Jacob, 2010a.

ANSERMET, François. Continuité et discontinuité, entre neurosciences et psychanalyse. Fondation Agalma: 24 de maio de 2018. Disponível em: https:// www. youtube. com/watch?v=-3GNY_BKif4, acesso 15 dez 2019.

ANSERMET. François. Le symptôme entre neurosciences et psychanalyse. Disponível em: https://www. youtube. com/watch? $\mathrm{v}=\mathrm{i} 6 \mathrm{wZ} 4 \mathrm{VuM}$ n $\mathrm{V} 29$ mai 2019, acesso 4 abr 2020

BARTHES, Roland. Euvres complètes. Paris: Seuil, 2002.

BourgeOIS, J-P. Synaptoarchitectonie, sujets et questions interfaces. In: GOLSE, B., PuTOIS, O.; VANIER, Al.. Epistémologie et méthodologie en psychanalyse et en psychiatrie, Pour un vrai débat avec les neurosciences. Paris: Erès, 2017.

COMMISSION NATIONALE DE L'INFORMATIQUE ET DES LIBERTES (CNIL-France). Comment permettre à l'Homme de garder la main ? Rapport sur les enjeux éthiques des algorithmes et de l'intelligence artificielle, décembre 2017. Disponível em: https://www.cnil.fr/sites/ default/files/atoms/files/ cnil_rapport_garder_la_main_web.pdf , acesso 12 jan 2020.

Clouzot, Henry-Georges, Le mystère de Picasso. Paris: Magnus Opus, 1956.

DAMOUR, Thibaut.http://www.doublecause.net/index.php?page=Thibault_Damour.htm, 2011.

Edelman, Gerald. Plus vaste que le ciel, Une nouvelle théorie générale du cerveau. Paris: Odile Jacob, 2004.

FlaUbert, Gustave. 3 janvier 1853. Les Amis de Flaubert. Bulletin no36, 1970, p. 33.

Flaubert, Gustave. Hérodias. Euvres complètes, Paris: Seuil, 1964.

FRAISSE, Luc. L'ouvre cathédrale : Proust et l'architecture médiévale. Paris: Corti, 1990.

GOLSE,B., Putois O.; Vanier, A. Epistémologie et méthodologie en psychanalyse et en psychiatrie, Pour un vrai débat avec les neurosciences. Paris: Erès, 2017.

Henrot, Geneviève, Poétique et réminiscence : charpenter le temps, Marcel Proust 3, Nouvelles directions de la recherche proustienne 2. Paris : Minard, 2001.

Proust, Marcel, Du côté de chez Swann, À la recherche du temps perdu Combray Premières épreuves corrigées 1913 Introduction et transcription de Charles Méla. Paris: Gallimard, 2013.

PRoust, M., No caminho de Swann, Em busca do tempo perdido. Trad. Mario Quintana. São Paulo: Globo, 2006.

Proust, M., A fugitiva, Em busca do tempo perdido. Trad. Carlos Drummond de Andrade. São Paulo, Globo, 2012.

Proust, M., O tempo redescoberto, Em busca do tempo perdido. Trad. Lúcia Miguel Pereira. São Paulo: Globo, 2013.

Rovelli, C. Sept brèves leçons de physique. Paris: Odile Jacob, 2015.

ROVELLI. L'ordre du temps. Paris: Flammarion, 2018b

VALERY, Paul. Variété. CEuvres complètes, T. I. Paris: Gallimard, 1957. 